\title{
Managers Productivity Language Method and Qualitative Management Standards (QIMS) in Healthcare Campus Organization
}

\author{
Efrat Danino \\ Shamir- Assaf Harofeh Hospital Campus Management \\ Michal Asaf Kremer \\ Independent Consultant
}

Qualitative Management Standards (QIMS) is a representative title for the novel methodology that was created during the organizational development process at the Shamir Academic Campus during 2019-2020. QlMS consolidates by Dr. Danino the Academic Campus manager and a specialist in Healthcare systems and Dr. Asaf Kremer an expert consultant for organizational development (OD), the creator of the MPL (Managers Productivity Language) methods for Excellency in leadership, which are being implemented among leading organizations in Israel

The OD process was conducted using Managers Productivity Language guidelines, and tailored towards the campus urgent needs, considering the campus vision as well as the leadership team associated with it.

This article addresses three main subjects:

Part 1: Introduction: MPL- The rationale for the campus organizational development program.

Part 2: The process: A description of the multidimensional organizational development process.

Part 3: QMS: The novel approach that was developed during the Organizational Development process, which is referred to as "QIMS" in this article, which improves action in qualitative and quantitative terms in the health system.

Keywords: managers developments, qualitative standard, healthcare, medical campus, organisational development, leadership, productivity, efficiency, decision making, cultural competency, training, productivity diamond, managers productivity language (MPL)

\section{INTRODUCTION: MPL- THE RATIONALE}

MPL (Management Productivity Language) (Asaf-Kramer, 2016-2020) is a novel method that provides the perception, knowledge, tools, and skills necessary for developing productive leadership at the personal and organizational level and is implemented in leading companies and organizations in Israel. The rationale of the method is based on innovative studies in the field of managerial development that rely on the Meaning approach (Frenkel, 1947) and complement one another with the various emphases that lead to their actual implementation, including Stephen Kobi (2017) who presents the strive for productivity by developing awareness and responsibility for creating an overall quality of life for managers, Arieli (2018) who 
emphasizes the importance of internalizing the factors for creating motivation, cooperation and perseverance for success and excellence, and Goldsmith (2017) who emphasizes the need to implement tools and skills among managers and the organization in the long term, as opposed to a culture of increase in training and acquiring knowledge at the expense of a thorough assimilation.

"There is no doubt that there is a need for a fourth-generation ... For a new paradigm and a new approach that does not differ in level but in essence - A thorough detachment from ineffective ways of thinking and acting ... We need a revolution and not an evolution. We need to move beyond time management to leading life - To a fourth, generation that is based on a paradigm that will lead to the creation of results emphasizing quality of life... "(Kobi, 2018, p. 36)

The innovation core ideas of the 'Productivity Language' developed and based on the 70th' Research ${ }^{1}$ (Asaf-Kremer, 2017-2019), a unique management study that examined the perceptions of 70 executives from various fields in the Israeli industry regarding productivity led excellence in management.

The 'Productivity Language' method provides a solution on the individual as well as on the organizational level, by embedding the perception, knowledge, tools, and skills required in dealing with the significant challenges faced by managers in the dynamic workplace that frequently strive for innovation and achievements through a focus on four different aspects (The 70th Research, Asaf-Kremer, 2017):

1. Creating a collaborative environment in situations of intercultural gaps as well as gaps of different personality types.

2. Effective resource management study with an emphasis on a qualitative decision-making process regarding time, energy, and human capital constraints.

3. Connecting to a motivation that emboldens all parties in the workplace.

4. Establishing an environment of creativity leading to innovation in the existing organization.

At the core of this method lay four basic principles on which the process of connecting and embedding on the personal and organizational level is taking place.

\section{FIRST PRINCIPLE: RECONNECTING TO VCGD (VISION-COMPASS-GOALS-DECISIONS IN REALITY)}

The principle refers to the accuracy of the personal and organizational 'Compass'. The vision is the depiction of the future or the beacon that points the direction and the way. According to the VCGD model, the vision is formed in a shared and encompassing process of the individuals in the organization and does not end in its mere formulation but in decision-making and courses of action. The process of creating the vision is meant to be creative, emotional, and not simply rational. The vision creation phase speaks of a type of contract that team members pledge individually as well as between each other and the organization, thus actually ensuring their course of action, and are engaged throughout the period in promoting it. As part of that, the process of creating the vision also includes a statement of personal vision, dealing with personal goals and organizational goals, as well as translating the vision to decision-making regarding goals and practical steps, i.e. decisions in reality.

\section{SECOND PRINCIPLE: A HOLISTIC APPROACH - PRODUCTIVE MANAGEMENT IS MORE THAN JUST TICKING A ' $V$ '}

In the challenging and dynamic modern workplace, it has become evidently clear that 'being productive is more than just ticking a V ... 'but is a lot more than that. In today's evolving and dynamic world, managers are required to have integrated and complex skills. The online Webster Dictionary defines productivity with several expressions in different levels, including expressions that refer to the extraction of maximum production out of efficiency, expressions that deal with the potential to produce and the productivity inherent in it, as well as those that metaphorically describe productivity as an action of impacting one's 
environment. "Igniting a spark with your productivity" ... The principle of the holistic approach to the "Productivity Language" indicates the existence of three different dimensions to productivity: The known functional dimension that focuses on efficiency and output; The qualitative dimension - That focuses on the potential to produce, as well as the energetic dimension that refers to the creation of a productivity spirit of leadership and working groups in the organization which is based on a connection to meaning, fostering long-term motivation, loyalty, and professionalism out of choice and appreciation on the part of the individual and organizations. The "Productivity Language" aims to strengthen the energetic dimension, which tends to dissipate in a lot of companies and organizations in modern times and promote the three dimensions simultaneously.

\section{THIRD PRINCIPLE: 'PRODUCTIVITY DIAMOND' - EMBEDDING APPLICABLE TOOLS}

Applicable tools are a purposeful principle that refers to the embedding of specific skills. 'The Productivity Diamond' is one of the innovative developments that emerged from the 70th Research (Asaf -Kremer, 2017) which found that the four shared challenges facing executives in companies and organizations are: The challenges of motivation, cooperation, resource management, and of creativity leading to productivity.

\section{FIGURE 1 \\ THE PRODUCTIVITY DIAMOND}

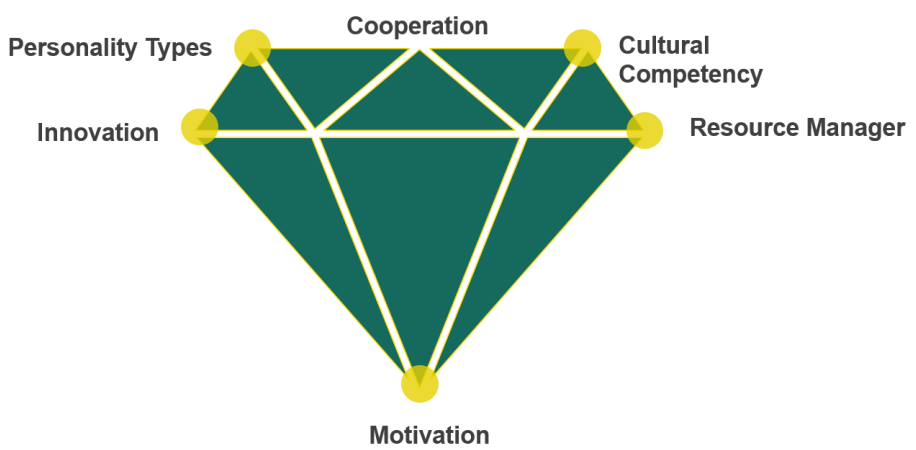

The 'Productivity Diamond' consolidates these challenges into an applied model that provides a real and long-term solution to these challenges by assimilating knowledge, tools, and skills.

\section{FOURTH PRINCIPLE: PROCESSES OF EVALUATION AND CRITICISM OF KNOWLEDGE ASSIMILATION - THE MPL INDEX}

The method establishes and assimilates the learning process of applicable tools, which help in longterm processes of bona fide change while dealing with environmental triggers.

Out of understanding that executives go through a plethora of courses and training of varying levels during their careers in order to gain competencies and further develop their managerial skills, from which it seems that their effect and influence is manifested usually only in the short term and usually not noticeable in the long term. This principle raises the importance of the effectiveness of training which is measured as stated in the long-term application of knowledge in practice.

The MPL index includes periodic feedback, narrative interviews, and periodic observations. Application of the MPL index in companies and organizations (Institute for Leadership in the IDF, Amdocs) proves that the language of productivity contributes to raising the level of long-term productivity in various fields with an added value of about $20 \%$. 


\section{THE PROCESS - ASSIMILATION OF MPL IN THE ASSAF HAROFE ACADEMIC CAMPUS AND CREATING QMS}

We have embarked on a common journey at the end of 2018. Step by step, we built a bespoke and precise intervention model for the entire campus.

The intervention process was activated gradually, starting from pinpointing of the organizational vision and the connection of the team to it, through the search of the burning needs that exist among the members of the organization and by assimilating the exact responses necessary for the team members in particular and the organization as a whole.

The program was delivered from the onset via a comprehensive spiral process that encompassed all parts of the organization: Campus management, middle management, and the entire staff and students.

In the next part, we shall describe how we have assimilated the four basic MPL principles in the Shamir Academic Campus.

\section{FIRST PRINCIPLE: RECONNECTING TO VCGD (VISION-COMPASS-GOALS-DECISIONS)}

\section{The Starting Point Is the Connection to the Personal and Organizational 'Compass'}

The connection to the personal and organizational 'Compass' took place in two steps that complemented each other: The first step is on a personal level - A connection to the personal vision of the campus manager, Dr. Danino as well as that of the leadership group on campus.

The second step, on the organizational level - A connection to the organizational vision as per its definition, evaluation of relevancy and validity, followed by making the necessary change in light of the progress that has taken place in the field of health in terms of dynamism and complexity nowadays. Also, from the vision, new relevant goals and objectives were derived from which the campus operates.

The new vision emphasizes the multiculturalism and diversity motif, emphasizes the importance of continuous learning and the desire to lead innovation in the field of nursing (Appendix 1)

A new personal vision leads to an innovative organizational structure - the previous organizational structure of the campus was conducted according to a traditional model of a three-tier pyramid that includes a senior management tier and below it a tier of deputies and the entire staff.

FIGURE 2

THE OLD ORGANIZATIONAL STRUCTURE AT SHAMIR ASSAF HAROFE CAMPUS

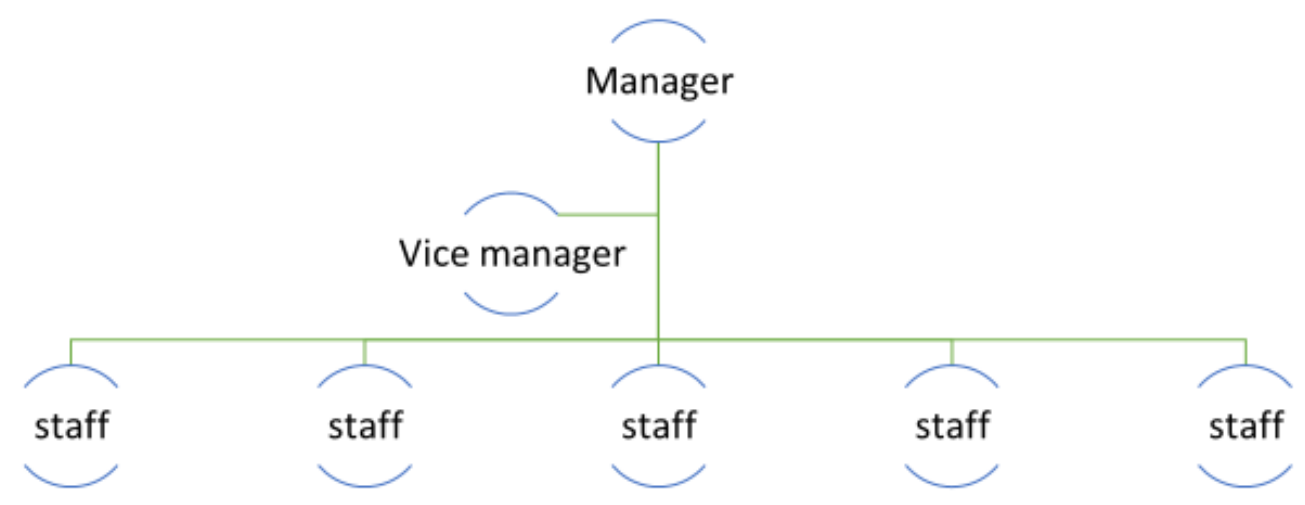

Efrat Danino: When I began my work in the management of the academic campus Shamir -Assaf Harofe for nursing, I led a process of mapping - Preservation - Improvement, which began with interviews of all staff members, a management exercise to examine the professional maturity of all staff members and examining teamwork processes. 
I had observed that the staff working at the school were burnt out, in a situation without any professional future prospects, working in a reality of operational difficulty and inability to leverage the quality of teaching as well as the leadership of students both in qualitative and quantitative terms.

In light of this, I made a change at two levels, on the one hand in the senior professional team, and the other in the junior multi-professional team. I created a hierarchy of action rather than a one-size-fits-all division. A situation that enables a sweeping ability for every employee to create a professional horizon, to advance and promote oneself on the one hand, while combining the promotion of the quality of teaching and the quality of professional work. This means looking at two aspects: On the one hand, an emphasis on team input and, on the other hand, an emphasis on promoting quality and professional work. In light of this, a new organizational structure was built, which enables both the promotion of a team to a professional and interesting direction and the promotion of professional and quality work adapted to the reality on the ground.

\section{FIGURE 3 \\ NEW ORGANIZATIONAL STRUCTURE}

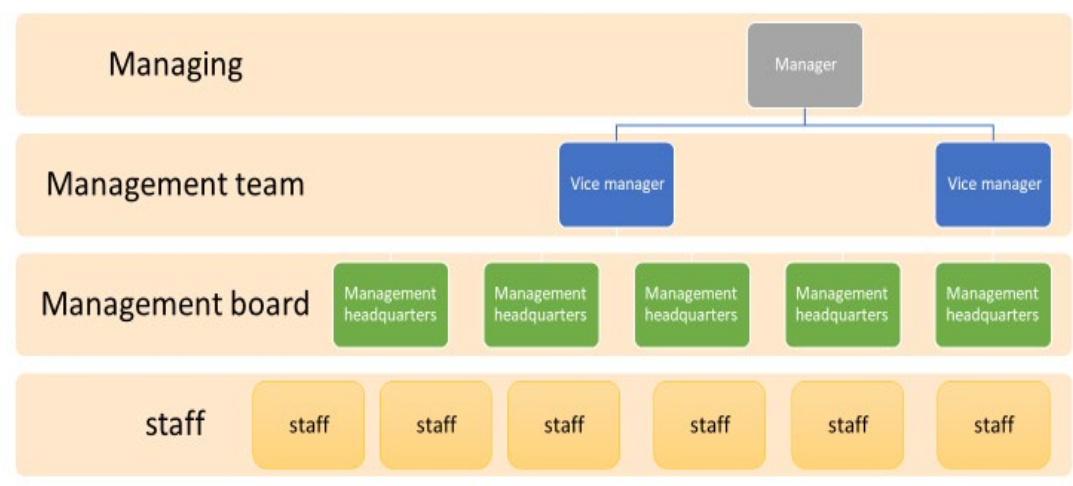

In light of this, forums have been built that also put the needs of students before their eyes, such as a conservation and support forum and a curriculum forum, which deal with leading and promoting students, both quantitatively and qualitatively, and at the same time leading processes adapted to reality and progress in nursing and in general.

This organizational structure enables the creation of a professional direction for each member of the staff, and at the same time allows students and organizational partners to respond to the promotion of innovative curricula, technological assimilation accompanied by research. 


\section{FIGURE 4}

\section{INNER ORGANIZATIONAL STRUCTURE}

\section{ORGANIZATIONAL STRUCTURE}

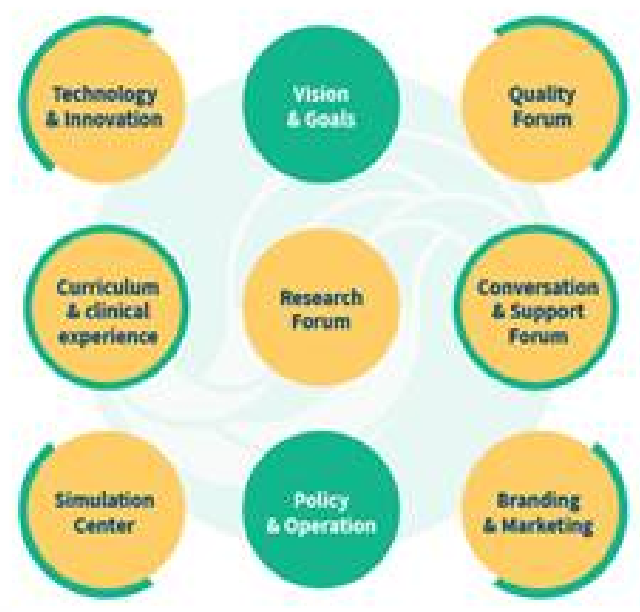

In each forum, work processes were carried out along with relevant parties and innovative thinking for solution and promotion. The following are the main points of innovation developed during the period in which the new organizational model was implemented according to the seven forums:

- Conservation and Support Forum - A drop-out monitoring tool was built, as well as monitoring over resources provided to students

- Technology Forum - A procedure was built for computerized intaking and guiding of students, and online work of theoretical instruction

- Simulation Center - A Gantt chart was built and monitored for the execution of courses, as well as a tool for improving the quality and increasing the number of learners and courses, as well as leading courses for diverse populations

- Marketing and Advertising Forum - Innovatively built in Israel on academic campuses for nursing. We built significant work processes, campaigns, branding, and marketing that helped triple the number of students on campus.

- Quality forum - works in parallel with all forums where each work process is examined using quality control tools

- Research Forum - Promotion of research that mainly deals with vocational education and the implementation of interventions on campus.

Michal Assaf-Kremer: From the very beginning of the professional accompaniment process, I was exposed to excellent work that included locating and focusing on the main areas of work to push forward and the various possibilities for promoting staff members that were performed and presented to the director Efrat. I recognized great potential in the attachment image (see picture number 3 ) that were formulated about the topics marked as important to push forward, a sort of organizational 'compass'.

My recommendation was to 'revive' the big picture into reality, no less and no more. The main recommendations for implementation concerned the creation of additional new leadership positions and harnessing the motivation of all team members to promote the ideas.

As part of the new creation process, new leadership roles were created for the 'Forum Head' positions who were in charge of the various areas, and all campus staff members were grouped as active 'Forum Members' in the various forums. At the end of the process, all the staff of the academic campus was 
associated and staffed to promote a certain area of work, according to their personal and professional inclination, in addition to their ongoing routine work.

A number of things have actually materialized in reality: The various forums are entrusted with the promotion of the specific field in which they are engaged both by using previous experience and by acquiring new knowledge leading to innovation in the field; Furthermore, the heads of the forums together were grouped to what has been dubbed the 'managerial headquarters' whose role is to be a helpful and leading thinking group in areas where strategic decision-making, promotion of collaborations and joint problem solving are required.

\section{THE SECOND PRINCIPLE ACCORDING TO THE MPL: A HOLISTIC APPROACH - PRODUCTIVE LEADERSHIP, MORE THAN JUST TICKING A V}

The assimilation of the principle of the holistic approach is reflected in the training provided to the entire team from a perspective of partnership and transparency towards the team in the work process. The overarching goal of the training was to promote the quality of life of staff members in general and to develop the quality of output in their professional tasks on campus in particular.

The training included 12 workshops that were constructed in a manner tailored to the needs of the participants and the organization. The sessions were delivered in modules that were a combination of a frontal lecture that imparts new knowledge, a workshop of practical application tools, and the assimilation of knowledge through a case study and content brought by the participants, which were based on their experience.

The content which was delivered dealt with issues of resource management with an emphasis on decision-making skills regarding time, energy during stressful and routine times and human capital, interpersonal communication in places of intercultural gaps and personality types, meaningful motivators, and factors encouraging or discouraging motivation as well as the topics of creativity and collaboration within heterogeneous work teams.

The practical emphases conveyed contributed to the perception of work tasks by reconnecting to their meaning and importance in addition to the dimension of urgency that the current routine reflects and encouraged the creation of a holistic work-life balance approach, and self and work development in order to contribute to the balance of self-fulfilment along with an atmosphere of productivity within the team.

\section{THE SECOND PRINCIPLE ACCORDING TO THE MPL: 'PRODUCTIVITY DIAMOND' - ASSIMILATING APPLICABLE TOOLS}

\section{THE PRODUCTIVITY DIAMOND}

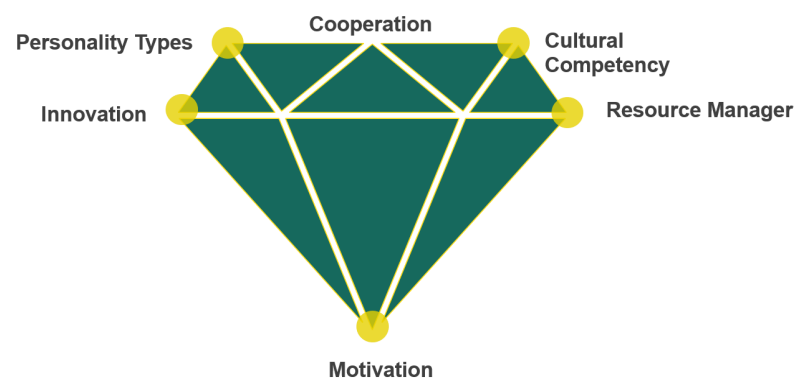

In line with the recommendations of the 70' th Research' (Asaf Kramer, 2018), the organizational development axis on campus has maintained four constant work areas: Collaborations, a connection to a meaningful motivation, resource management, and innovation-leading creativity. 
The Development Axis of Collaborations focused on reducing situations of poor teamwork in which there is little cooperation between the members of the management staff who, in the bottom line, impair the leadership and execution of significant moves and projects in the organization.

The Resource Management Development Axis dealt with decision-making regarding time, human capital, and personal energy. In light of the many irrational biases that are covertly and overtly involved in the decision-making processes, as well as in light of bad habits that are rooted within these processes, there has been a dire need to establish an applied leadership decision-making strategy.

In this regard, the productivity diamond has provided innovative applied practice through the 'Productive Model for Decision Making' (Assaf-Kremer, 2017) which has been studied in leading companies and organizations in Israel and has been accepted for publication academia internationally (Israel Presidential House and Cambridge UK). The productive decision-making model teaches an educated and rational decision-making process that considers various aspects including the emotional, political, and bureaucratic aspects necessary for optimal decision-making in any situation.

The Meaning Based Motivation Development Axis addressed the difficulty of middle managers primarily who face significant difficulty themselves and their environment in connecting to long-term motivation in their work. The training directed the participants to find the connection to full motivation, which raises the level of impact on the environment, contributes to achieving the goals positively and creatively, and contributes to success and excellence both with tasks and with people.

The Innovation Led Creativeness Development Axis focused on learning the conditions for an environment that encourages creativity, on a personal and organizational level. Such creativity is a required component in work environments especially today, both for resolving interpersonal conflicts that stem from cultural backgrounds or personal gaps and for creating innovation in a field that belongs to the health system, a complex and organizationally branched system, where norms and practices are mostly traditional.

\section{FOURTH PRINCIPLE: EVALUATION AND AUDIT PROCESSES - MPL INDEX}

The organizational development process, including the development of managers in the academic campus, included the assimilation of conceptual knowledge, applied practical tools in order to perfect the personal skills of the staff members, and provide a real and long-term solution to challenges at the organizational level. The application of the MPL index principle is expressed in two parallel ways:

1. The MPL index for examining the implementation of the 'Language of Productivity' method Examining the connection of the participants in the training to the study topics as well as an assessment of the degree of application of the concept, knowledge, and practical tools conveyed in the various forums to staff and management.

The results of the index: At the end of the first year in the process, the MPL index indicated $80 \%$ satisfaction of the staff regarding the accuracy of the content.

$75 \%$ satisfaction with the level of assimilation of the team and use of the tools learned

$80 \%$ satisfaction with the innovation created in their work following the training

2. Holistic organizational research process

Listening to the voices raised in the various training and meetings, the need arose to map the situation on campus in terms of perceptions and attitudes toward success. In the process, it was decided to conduct organizational research that will help map the standards for quality management on campus from a holistic perspective, both of the staff and the students. The chosen method of execution is a combination of cross-sectional research (survey) for students, staff, and narrative in-depth interviews with staff members.

Cross-sectional study for students (survey) - Already during the month of August 2019, online feedback was built which was specially adapted to the needs of the campus and was delivered in a centralized manner to the students.

A questionnaire was administered to nursing students from the four-year academic program, academic conversions, and basic courses. The survey was sent in a Google file, the response rate was $40 \%$, and student 
satisfaction was on a 1 (lowest) to 5 (highest) scale. Responses from the student secretariat, academic advisors, teaching assistants, and the cleaning staff were high, with an average of 4 .

A sense of a supportive and helpful environment was also high (average of 3.9). The level of theoretical instruction among the staff was noted at an average of 4 . The sense of transparency for students among the management was high (average score of 4 ).

Cross-sectional study for staff (survey) - Concurrently, an Internet questionnaire was administered among all the teaching staff of the Shamir Academic Nursing Campus, to which the level of response was $63 \%$. The questionnaire included follow up questions that the faculty was asked to answer on a scale of 1 to 5 ( 1 - Does not agree at all; 5 - Fully agree)

The questionnaire included components of Professional development and promotion of the teaching staff; A practice of quality teaching-learning assessment; Warm and caring relationships between teachers and students; Job satisfaction of campus work and conduct; A sense of protection on campus; Teamwork on campus; Campus efforts to promote tolerance and acceptance towards the other and the different.

The results of the survey showed that the majority of the staff $(75 \%)$ felt that there was an adequate response and a desire for personal improvement and development of the entire team at an individual and more general level. In addition, that the campus manager is perceived as a partner in the personal development of most faculty members through the construction of a personal work plan and its actual implementation. In addition, faculty members felt that teaching practices are diverse and are required to diversify teaching strategies and that they are given tools to do so $(65 \%)$. Campus staff $(80 \%)$ expressed general satisfaction with the conduct of the campus and its work in favor of improving campus conditions and conditions for success at work. The staff's sense of protection from students was low, $75 \%$ fearing student conduct. Teamwork was high and $60 \%$ of staff felt satisfied with teamwork. While the sense of closeness and caring and the desire to promote it among the faculty was particularly high (85\%).

\section{Narrative Interview for Staff Members}

Another tool that we used which was brought up by one of the staff members of the management staff is narrative interviews with the team about their perceptions towards the concept of success.

During the month of September, narrative interviews were conducted for a third of the team members (13) who dealt with existing positions and perceptions regarding success and the standards for achieving it. The collaboration was at a high level $(90 \%)$ and the study findings revealed a diverse picture of the respondents' perceptions and attitudes towards high-quality standards for achieving success, as well as towards the strengths and weaknesses of the campus.

The analysis of the interviews revealed four points of interest to consider:

1. Different perceptions and attitudes towards the concept of 'Success': "Success" was defined as both an existing experience and an aspiration for the future. For example:

"To succeed is to achieve my ambitions"; "Success for me is not merely a V tick and hearing that they are satisfied with my work ..."; "Success for me is a feeling of wellbeing ..."; "Success is a sense of control over my physical, mental and social life" ...; "Success for me is to rise up and not to put down others in the process" ...; "When a person knows how to take data, process it and create something good and right from a professional point of view, and also implement it ..."; Success is that the course is conducted properly in all respects ... ";" ... To succeed in human relationships and communication ... ";. .. "To receive good feedback from the management, that the recipients of the service will be satisfied, the staff will be satisfied, feeling a flow of good atmosphere ..."; ... "Success is to meet quantitative goals in some peace of mind .."

2. Themes that created the pillar of QIMS (Qualitative Management Standards): (1) Management support for personal and professional development $(100 \%)$; (2) Openness to innovation and change (80\%); (3) Setting and achieving challenges (90\%); (3) A sense of involvement and partnership (100\%); (4) a positive level of communication between staff, between staff and students, between students and themselves (80\%) (5) A significant sense of 
influence (90\%); (6) Resource management for optimal quality of life - Time, work force, energy $(80 \%)$.

3. In summary, the points of strength that were perceived could be described as a common perception among the team regarding a high level of support from management regarding encouraging personal and professional development (100\%) and setting and achieving challenges (90\%). In addition, there is a sense of involvement and partnership (90\%) and the perception of management as open to innovation and change $(80 \%)$ and as a general appreciation (about $70 \%$ )...

4. In summary, from the points of weakness that were perceived it is clear that there is a common perception regarding the need to improve resource management until reaching a standard level (time, order, quiet, manpower assistance) (80\%), as well as establishing positive team communication $(60 \%)$ in light of the pre-existing segmentation into teams, and the lack of common and fruitful dialogue.

FIGURE 5

THE IMPLEMENTATION OF 'PRODUCTIVITY LANGUAGE'

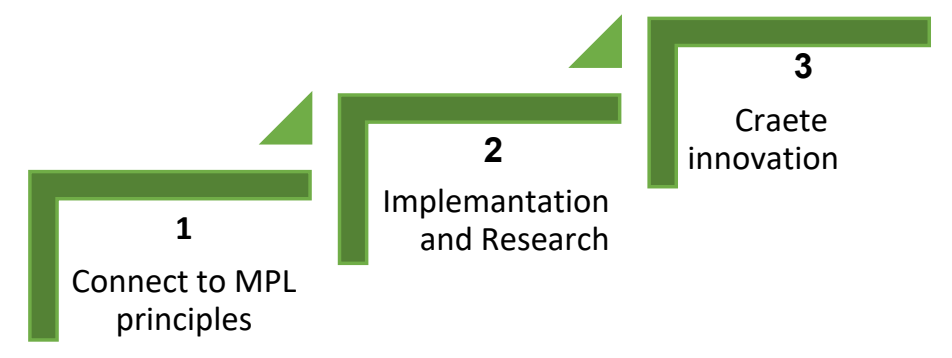

\section{INSTITUTIONALISING QUALITY MANAGEMENT STANDARDS (QMS)}

From a general perspective of the process, the following three significant benefits can be identified:

\section{Two Levels of Assimilation}

The process of assimilating the 'language of productivity' is evident both in the day-to-day routine and in specific cases and has promoted the quality of work at both levels. At the current routine level - One can see the connection to the method through the newly created language, work procedures, and organizational atmosphere. The common language - - The tools learned, and the application of the skills created a broader common denominator of a conceptual framework in teamwork and collaboration. For example, in meetings and team gatherings one can often find the concepts of 'Important-Urgent', 'Functional levels of personality type', 'Holistic vision', 'SWOT', 'Productivity', 'Connection to meaning', 'find out our WHY', and more.

In terms of work procedures - The connection to the spirit of the language of productivity has led to the holding of periodic personal status meetings between the campus manager and staff members, where a response of a broad professional and personal approach was given, emphasizing self-fulfilment and optimal self-realization for the employee and organization. Another example of the work done within the forums, which are outlined by building work plans with a situational status, striving to promote the QMS ideals in the annual work centers (Collaborations and resource management) while frequently using the newly acquired tools and concepts. 


\section{On a Localized Response Level}

The work process provided a focused response to the various challenges that arose along the way at the level of the individual and the organization. At the individual level, a thorough focused response was given to addressing the difficulties encountered by forum administrators in personal management and management of others by supervising and a close personal mentoring for several days by the campus director and by providing personal training sessions as a point response to a challenging matter raised by the accompanying consultant Michal.

At the organizational level - It is impossible not to mention the great challenge the system faced because of the Coronavirus crisis. As a result of the cumulative distress that arose in the team regarding the difficulty of working in conditions of uncertainty, the training sessions were adapted to provide a unique response to the need that arose. The meetings that took place in June in which the entire extended team (about 30 people) participated dealt with making decisions with certainty and creating an optimal work map within them, as well as the challenge of fostering collaborations at work in light of the differences in terms of personality types and ways to strengthen collaborations among these.

\section{Five Shared Principles Leading to Five Periodical Quality Management Standards}

The manner in which the entire process was held has maintained listening to people in the 'field', transparency as well as consistency in focusing and conveying the messages regarding the principles and focal points desired in the organization. Examination and listening to the voices that came up in the process during the meetings that took place with the management and with the general staff, raised the need to emphasize the qualitative aspect of the work.

The personal counselling meetings between us in light of the deep and thorough knowledge of the campus director Efrat Danino with the existing needs in the field, from her extensive knowledge and experience in general leadership and leadership positions in the health system in Israel, as the professional development and research director at the new Assuta Ashdod Hospital, as well as the director of the nursing system in the pediatric ward, at Hadassah Ein Kerem Hospital, led to the launch of the novel initiative we named ' Quality Management Standards' (Q1MS) which are currently part of the campus' decision-making and ongoing work processes.

Today, on-campus, the five following standards are underlined as periodic QMS:

1. Maximal cooperation between the members of the forums and between the various forums and the whole team as a way of action

2. Maximal transparency in management and decision making

3. Consistency in areas of action - Focusing on long-term and short-term tasks while locating and dealing with distractions

4. Optimal, respectful and empowering interpersonal communications

5. Flexibility and enabling of diversity and differences in order to achieve a harmonious and inclusive atmosphere among all

\section{Internal-Organizational Research}

Conducting annual organizational research that included analysis of findings and producing meaning to staff and management has contributed to getting a sense of a complex picture for group characteristics, perceptions, and attitudes of staff and students and enabled a real focus of the standards required for success that were considered. Internal Organizational Research was adopted as an internal and significant tool that will be run at an organizational level periodically in order to allow for the momentum of reading the current map as well as updating and focusing on the actual QMS (Quality Management Standards) accordingly.

\section{Building a Focus Group of Shared Leadership}

The significant process has led to the creation of a focus group oriented towards shared leadership, which will examine voluntarily students, alumni, and staff members who wish to take part and be partners in the continuation of the thought process and work in this area. The focus group will lead and establish on a basis of connecting to the meaning of the process and its importance. 
The progress that will be made through the working meetings with the focus group during the coming months will be accessible to the wider staff and the student audience and will be processed later for learning methods that will be integrated into the general curriculum.

\section{SUMMARY AND CONCLUSIONS}

In this article, we have outlined the development organisational process in a manner that produces a novel methodology, the highlight of which is quality management standards (QMS). The methodology represents the innovation created during the organizational development process on the Assaf Harofe Academic Campus (2019-2020) that promoted the personal and organizational leadership of the campus staff, in their various roles and statuses, and was conducted in the spirit of the 'Productivity Language' method with accordance with the needs and nature of the organization in collaboration and coordination between us.

From dealing with the three pillars of rationale, the process, and assimilation of innovation, we have chosen several main points to emphasize which we have found to be significant to the summary and future recommendations:

\section{Openness Towards Change or Updating of Perceptions as Well as an Organizational Renewal in a Complex System With Traditional Procedures}

There is a significant need for a new paradigm among health organizations in Israel whose main ideals will be a combination of qualitative standards for success in conjunction with quantitative data. The three goals that we recommend supporting and promoting in light of the research and of the situation on the ground, are:

(1) Support of management in personal and professional development; (2) A high level of interpersonal communication that will support collaboration between the staff member, between staff members and students, and between the students.; (3) A constant improvement in resource management for optimal quality of life - Time, manpower, people.

The significant change made on campus, in light of the new organizational model built and implemented, is in fact an example of building a broad platform for realizing the organizational vision and goals derived from it. The new model expands opportunities for the advancement and progression of additional staff members and expressions of personal leadership among staff members with experience and motivation alike, as well as creating organizational innovation and leadership in the field of healthcare.

The success of the work in general contributes to strengthening our belief in the importance of empowering people with motivation and leadership skills in organizations, who express their desire to lead and promote people and the field in general. The organizational change on the Assaf Harofe campus has become an excellent example of teamwork as a recipe for success in promoting fields and fostering innovation, as well as improving collaboration skills and creating a positive and even fun atmosphere in the shared work environment.

\section{Organizational Terminology That Connects to the Updated Organizational Vision on to the Periodic QMS}

The assimilation of the organizational process and the changes derived from it were supported by the creation of a new common terminology. The new organizational terminology emphasizes and supports the focus on the five periodic QMS's in every part of the work routine and frequently emphasizes: Maximal cooperation between forum members and between the various forums and staff; Maximal transparency in management and decision making; consistency in action centers; Flexibility and enabling differences and diversity in order to achieve a harmonious and inclusive atmosphere among all. 
Implementation of the concepts learned in the various team training and their establishment in the current organizational language through frequent use during routine, are significant components in the assimilation of the desired innovation and overcoming the environmental triggers that inhibit development and change.

\section{An Understanding That Creativity Leading to Innovation Is Possible Through the Collaboration of Different Fields}

The success of our shared work symbolizes the potential success that lies in collaborations between professionals who are experts in various fields. In our specific case, a collaboration between the strategic consulting of Michal - An expert in decision making and executive facilitator for leadership development in leading companies and organizations in Israel, including global business companies and security forces, and Efrat - The director of the academic campus at Assaf Harofe, a leading expert in health organization management in Israel.

It is evident that the contribution inherent in combining a variety of professions, a variety of endeavors, and a variety of human diversity is significant and valuable and can lead to major breakthroughs in organizations and companies alike. The innovation created in our work could not have been created without our true willingness to cooperate while listening to each other, with a level of honesty and respect in personal communication, while allowing for the personal strengths and resources each brings with them from their professional experience and life journey.

Moreover, indeed, several months ago, the joint work of all us received special positive reinforcement from the Israeli Ministry of Health, while the Shamir Academic Campus received a certificate of excellence for its achievements as a leading campus in Israel.

\section{ENDNOTE}

1. A research that conducted by Michal Asaf Kremer that deals with 70 managers and IDF officers in Israel (2017-2019) and with the findings that followed and reveals the cutting edge 'Productivity Diamond' model for developing Productivity Led Excellency (PLE)

\section{REFERENCES}

Asaf-Kremer, M. (2018). Foreign Decision Making Process. Britain: Cambridge Scholars Publishers. Retrieved from http://www.cambridgescholars.com/golda-meirs-foreign-decision-making-process

Asaf-Kremer, M. (2020). Productivity Diamond. RAIS conference at Johns Hopkins University. Retrieved from http://rais.education/wp-content/uploads/2020/04/0031MK.pdf

Ariely, D. (2009). Irrational and Not in Case; The Hidden Decision-Making Designed Factors. Tel Aviv: Matar.

Ariely, D. (2018). PAYOFF: The Hidden Logic That Shapes Our Motivation. Rishon Lezion; Chemed Publishers.

Clandinin, D.J. (2007). Handbook of Narrative: Inquiry Mapping a Methodology. Sage publications.

Covey, R.S. (1998). First Start First. New York: Simon \& Shuster Publishers.

Covey, R.S. (1989). The seven Habits of Highly Effective People. New York: Simon \& Shuster Publishers.

Denzin, N.K., \& Lincoln, Y.S. (2005). Introduction: The discipline and practice of qualitative research. Handbook of qualitative research. London: Sage Publications.

Edwards, R., Holland, J. (2013). What is qualitative interviewing? London, New Delhi, New York, Sydney; Bloomsbury Academic. pp. 2-3.

Fischoff, B., \& Beyth, R. (1975). I knew it would happen: Remembered Probabilities of Once Future Things. Organizational Behaviour and Human Performance, 13, 1-16.

Fontana, A., \& Frey, J.H. (2000). The Interview: From structured questions to negotiated text. In N.K. Denzin \& Y.S. Lincoln, Handbook of Qualitative Research. London: Sage Publications. 
Frenkel, V. (1981). Man's Search for Meaning. Tel-Aviv: Dvir Publishes.

Goldsmith, M. (2017). Triggers. Tel Aviv: Matar Publishing House.

Kahneman, D. (2013). Thinking, Fast and Slow. Or Yehuda; Kinneret, Zamora-Bitan.

Kahneman, D., \& Klein, G. (2009). Conditions for intuitive Expertise: A Failure to Disagree. American Psychologist Journal, 64, 515-26.

Kahneman, D., \& Lovallo D. (2005). In M. Bar-Hillel, Rationality and Happiness Careful choices and bold Predictions: A Cognitive Perspective on Risk Taking. Haifa: Keter.

Kahneman, D., \& Tversky, A. (1979). Prospect Theory: An Analysis of Decision under Risk. Econometrica, 47, 263-91.

Kremer-Asaf, M. (2018). Golda Meir's Foreign Decision-Making Process: An Analysis. Cambridge Scholars Publishers.

Mintz, A., \& DeRouen, K. (2010). Understanding foreign Policy Decision Making. Cambridge University Press.

Mintz, A. (2004). How do Leaders Makes Decisions? A Poliheuristic Perspective. Journal of Conflict Resolution, p.48.

Ricoeur, P. (1981). What is Text? Explanation and Understanding. In J.B. Thompson (Ed.), Hermeneutics and Human Science (pp. 145-64). New York; Cambridge University Press.

Robinson, K. (2014). Finding Your Element. Jerusalem: Keter Books.

Seligman, M. (2011). Flourish: A Visionary New Understanding of Happiness and Well-being. New York: Free Press.

Shkedi, A. (2014). The Meaning behind the Words; Qualitative Research Methodologies (pp. 37-143). Tel Aviv: Ramot, Tel Aviv University.

Shkedi, A. (2010). Educating reflecting teacher for teaching culturally valued subjects. Evaluation Research of Education, 14(2), 94-119.

Slovic, P. (2000). The Perception of Risk. Sterling, VA: Earth Scan.

Slovic, P., Fischhoff, B., \& Lichtenstein S. (1978), Judged Frequency of Lethal Events. Journal of Experimental Psychology: Human Learning and Memory, 4(6), 551-78.

Simon, H. (1992). What Is an Explanation of Behaviour? Psychological Science, 3, 150-61.

Simon, H. (1985). Human Nature in Politics: The Dialogue of Psychology with Political Science. American Political Science Review, 79, 293-304.

Simon, H. (1982). Models of Bounded Rationality. Cambridge: MIT Press.

Simon, H. (1957). A Behaviour model of Rational Choice. In H. Simon, Models of Man: Social and Rational. NY: John Wiley and Sons.

Sunstein, R., \& Timur, K. (1999). Availability Cascades and Risk Regulation. Stanford Law Review, 51. Cercla, The Comprehensive Environmental Response, Compensation, and Liability Act. pp. 66268.

Talb, N. (2009). The Black Swan. Or -Yehuda: Dvir Pub.

Tetlock, E. (2005). Expert Political Judgment: How good is it? How Can We Know? Princeton University Press.

Tetlock, E. (1985). Integrative Complexity of American and Soviet Foreign Policy Rhetoric: A Time Series Analysis. Journal of Personality and Social Psychology, 46(4), 85-156.

Tetlock, E. (1983). 'Policy Makers' Images of International Conflict. Journal of Social Issues, 39, 67-88.

Thaler, R.H. (1980). Toward a Positive Theory of Consumer Choice. Journal of Economic Behaviour and Organization, 39, 36-90

Tversky, A., \& Kahneman, D. (1974). Judgment under Uncertainty, Heuristics and Biases. In Rationality, fairness and wealth (2005). Keter; Haifa University.

Tversky, A., \& Kahneman, D. (1973). Availability: A heuristic for judging frequency and probability. Cognitive Psychology, 5, 207-32.

Tversky, A. (1972). Elimination by Aspects: A Theory of Choice. Psychological Review, 79(2), 207-32. 


\section{APPENDIX 1: ASSAF HAROFE CAMPUS VISION (2020)}

\section{Campus Vision - Shamir Assaf Harofe}

The Shamir Assaf Academic School of Nursing strives to lead the academic education for nursing in Israel. The school trains and educates nurses to a high level of professionalism through a bachelor's degree in nursing - Whose graduate nurses are at the forefront of leadership in public nursing, striving for professional, academic, and personal excellence.

A graduate of the Assaf Harofe Academic School of Nursing works out of humane values that emphasize human dignity, liberty, and uniqueness while achieving competency in the full body of knowledge of the field. An emphasis on independent principles and ways of learning is part of the learning process, which will allow the graduate to follow up independently on the constantly evolving literature in the field of nursing in the future. The fields of knowledge combine the natural sciences, technology and innovation, life, and behavioural science with nursing and medical knowledge, which emphasize the connection between body and mind. The studies from the various fields of science enable the development of the ability to conduct research and the use of the knowledge gained through them to empower and improve treatment, with an emphasis on cultural and linguistic sensitivity.

A graduate of the Assaf Harofe Academic School of Nursing must recognize and act in accordance with the code of ethics and preserve the rights of the patient and their family, as these are necessary basic values in every democratic society and certainly in Israeli society.

The Shamir Assaf Academic School of Nursing maintains mutual working relationships with the hospital and the community. All this, in order to improve and streamline the student is learning experience.

The school puts the student at the centre, and as such strives to create a learning environment that promotes and enables. 